Article

\title{
Tanshinone IIA Inhibits Epithelial-Mesenchymal Transition in Bladder Cancer Cells via Modulation of STAT3-CCL2 Signaling
}

\author{
Sung-Ying Huang ${ }^{1}$, Shu-Fang Chang ${ }^{2}$, Kuan-Fu Liao ${ }^{3,4}$ and Sheng-Chun Chiu ${ }^{2,5,6, *}$ \\ 1 Department of Ophthalmology, Hsinchu Mackay Memorial Hospital, No. 690, Sec. 2, Guangfu Rd., \\ East Dist, Hsinchu City 30071, Taiwan; hopes929@gmail.com \\ 2 Department of Research, Taichung Tzu Chi Hospital, Buddhist Tzu Chi Medical Foundation, No. 88, \\ Section 1, Fengxing Road, Tanzi Dist., Taichung City 427, Taiwan; fantac10@gmail.com \\ 3 Graduate Institute of Integrated Medicine, China Medical University, No. 91, Hsueh-Shih Road, \\ Taichung City 427, Taiwan; kuanfuliaog@gmail.com \\ 4 Department of Internal Medicine, Taichung Tzu Chi Hospital, Buddhist Tzu Chi Medical Foundation, \\ No. 88, Section 1, Fengxing Road, Tanzi Dist., Taichung City 427, Taiwan \\ 5 Department of Laboratory Medicine, Taichung Tzu Chi Hospital, Buddhist Tzu Chi Medical Foundation, \\ No. 88, Section 1, Fengxing Road, Tanzi Dist., Taichung City 427, Taiwan \\ 6 General Education Center, Tzu Chi University of Science and Technology, No. 880, Section 2, \\ Chien-kuo Road, Hualien City 970, Taiwan \\ * Correspondence: tc1271201@tzuchi.com.tw; Tel.: +886-4-3606-0666 (ext. 3430)
}

Received: 29 June 2017; Accepted: 21 July 2017; Published: 25 July 2017

\begin{abstract}
Tanshinone IIA (Tan-IIA) is an extract from the widely used traditional Chinese medicine (TCM) Danshen (Salvia miltiorrhiza), and has been found to attenuate the proliferation of bladder cancer (BCa) cells (The IC 50 were: 5637, $2.6 \mu \mathrm{g} / \mathrm{mL}$; BFTC, $2 \mu \mathrm{g} / \mathrm{mL} ; \mathrm{T} 24,2.7 \mu \mathrm{g} / \mathrm{mL}$, respectively.). However, the mechanism of the effect of Tan-IIA on migration inhibition of BCa cells remains unclear. This study investigates the anti-metastatic effect of Tan-IIA in human BCa cells and clarifies its molecular mechanism. Three human BCa cell lines, 5637, BFTC and T24, were used for subsequent experiments. Cell migration and invasion were evaluated by transwell assays. Real-time RT-PCR and western blotting were performed to detect epithelial-mesenchymal transition (EMT)-related gene expression. The enzymatic activity of matrix metalloproteinases (MMP) was evaluated by zymography assay. Tan-IIA inhibited the migration and invasion of human BCa cells. Tan-IIA suppressed both the protein expression and enzymatic activity of MMP-9/-2 in human BCa cells. Tan-IIA up-regulated the epithelial marker E-cadherin and down-regulated mesenchymal markers such as N-cadherin and Vimentin, along with transcription regulators such as Snail and Slug in BCa cells in a time- and dose-dependent manner. Mechanism dissection revealed that Tan-IIA-inhibited BCa cell invasion could function via suppressed chemokine (C-C motif) ligand 2 (CCL2) expression, which could be reversed by the addition of CCL2 recombinant protein. Furthermore, Tan-IIA could inhibit the phosphorylation of the signal transducer and activator of transcription 3 (STAT3) (Tyr705), which cannot be restored by the CCL2 recombinant protein addition. These data implicated that Tan-IIA might suppress EMT on BCa cells through STAT3-CCL2 signaling inhibition. Tan-IIA inhibits EMT of BCa cells via modulation of STAT3-CCL2 signaling. Our findings suggest that Tan-IIA can serve as a potential anti-metastatic agent in BCa therapy.
\end{abstract}

Keywords: bladder cancer; chemokine (C-C motif) ligand 2; epithelial-mesenchymal transition; signal transducer and activator of transcription 3 ; tanshinone IIA 


\section{Introduction}

Bladder cancer (BCa) is one of the most prevalent types of cancer and is the leading cause of death among patients with urinary tract disease [1]. In 2016, the United States alone recorded more than 76,000 new cases of $\mathrm{BCa}$ and 16,000 deaths [2]. Most BCa cases are diagnosed as non-muscle invasive tumors; however, $50-70 \%$ of these tumors recur frequently and approximately $15 \%$ eventually develop into muscle-invasive or metastatic $\mathrm{BCa}[3,4]$. Current treatment methods including radical cystectomy and systemic chemotherapy are effective in some muscle-invasive BCa patients, but $95 \%$ of metastatic $\mathrm{BCa}$ patients die within 5-years diagnosis, indicating the need for new therapeutic strategies [5].

Tan-IIA $\left(\mathrm{C}_{19} \mathrm{H}_{18} \mathrm{O}_{3}\right)$ is one of the major lipophilic compounds extracted from the root of a traditional Chinese medicine, Danshen (Salvia miltiorrhiza) [6,7], and has been used for the treatment of cardiovascular disease via its anti-oxidant and anti-inflammatory activity [8,9]. In addition, Tan-IIA has been found to exert antitumor activity in various types of cancer including osteosarcoma [10], gastric [11], lung [12], esophageal [13], and prostate cancers [14]. The antitumor activity of Tan-IIA mainly occurs through proliferation inhibition, apoptosis induction, and metastasis inhibition [15-18]. For instance, Tan-IIA increased CCAAT/enhancer-binding protein homologous protein (CHOP) and caspase-4 expression, and induced apoptosis of human esophageal Ec-109 cells via the endoplasmic reticulum (ER) stress pathway [19]. Tan-IIA induced cytochrome c-mediated caspase cascade apoptosis in A549 human lung cancer cells via the JNK pathway [20]. Tan-IIA caused apoptosis in human oral cancer KB cells through a mitochondria-dependent pathway [21]. However, Tan-IIA did not show significant cytotoxicity on human normal prostate epithelial cells (PrEC) and normal mammary epithelial cells (HMEC) at the concentrations high as $50 \mu \mathrm{M}[22,23]$. Also, the toxicity in normal tissues was not observed in Tan-IIA treated mice [24]. In our previous study, Tan-IIA was found to induce mitochondria-dependent apoptosis and suppress migration in BCa cells [25]. However, the mechanism by which Tan-IIA inhibits the migration and invasion of BCa cells remains undetermined.

Previous reports found a correlation of urinary CCL2 levels with tumor stage, grade and metastasis in patients with $\mathrm{BCa}[26,27]$, and patients with stages $\mathrm{T} 2-\mathrm{T} 4 \mathrm{BCa}$ were found to have a higher mean CCL2 concentration in their urine as compared to those with T1 stage tumors [27]. Previous studies also showed that CCL2 can regulate tumor progression and metastasis by altering the tumor microenvironment [28-30]. CCL2 induced epithelial mesenchymal transition (EMT) in order to promote tumor metastasis in various cancer types [31-33]. Down-regulation of CCL2 expression by inhibiting phosphorylation of STAT3 led to the suppression of metastasis in breast and lung cancer [34]. STAT3 signaling is an important pathway which is frequently activated in many tumors including $\mathrm{BCa}[35,36]$. The transcriptional activity of STAT3 is required for the phosphorylation at the tyrosine residue 705 (Tyr705) and has been demonstrated to be critical for BCa cell growth and survival [36,37]. In addition, activation of STAT3 promoted migration and invasion of BCa cells [38]. Thus, we seek to elucidate the role of STAT3-CCL2 signaling in Tan-IIA-induced EMT inhibition in BCa cells.

The results of the present study demonstrate that Tan-IIA inhibited the migration and invasion of human BCa cells. Tan-IIA inhibited EMT in BCa cells via the suppression of CCL2 expression which cannot be reversed by addition of CCL2 recombinant protein. In addition, Tan-IIA suppressed the phosphorylation of STAT3 (Tyr705), which cannot be restored by addition of CCL2 recombinant protein. Our data suggests that Tan-IIA might inhibit EMT in BCa cells through the STAT3-CCL2 signaling inhibition.

\section{Results}

\subsection{Tan-IIA Inhibits the Migration and Invasion of Human BCa Cells}

Human BCa cells were treated with $4 \mu \mathrm{g} / \mathrm{mL}$ Tan-IIA for $24 \mathrm{~h}$ and then subjected to migration $(24 \mathrm{~h})$ and invasion $(48 \mathrm{~h}$ ) assay (Figure 1A). In the migration assay, Tan-IIA decreased the number of migrating cells to $25.6 \pm 4.7 \%$ (5637), $32 \pm 2.9 \%$ (BFTC), and $70.5 \pm 9.7 \%$ (T24) as compared to the 
control group. In the invasion assay, Tan-IIA decreased the number of migrating cells to $11 \pm 2.9 \%$ (5637), $51.8 \pm 4.4 \%$ (BFTC), and $22.8 \pm 9.8 \%$ (T24) as compared to the control group.

$\mathbf{A}$
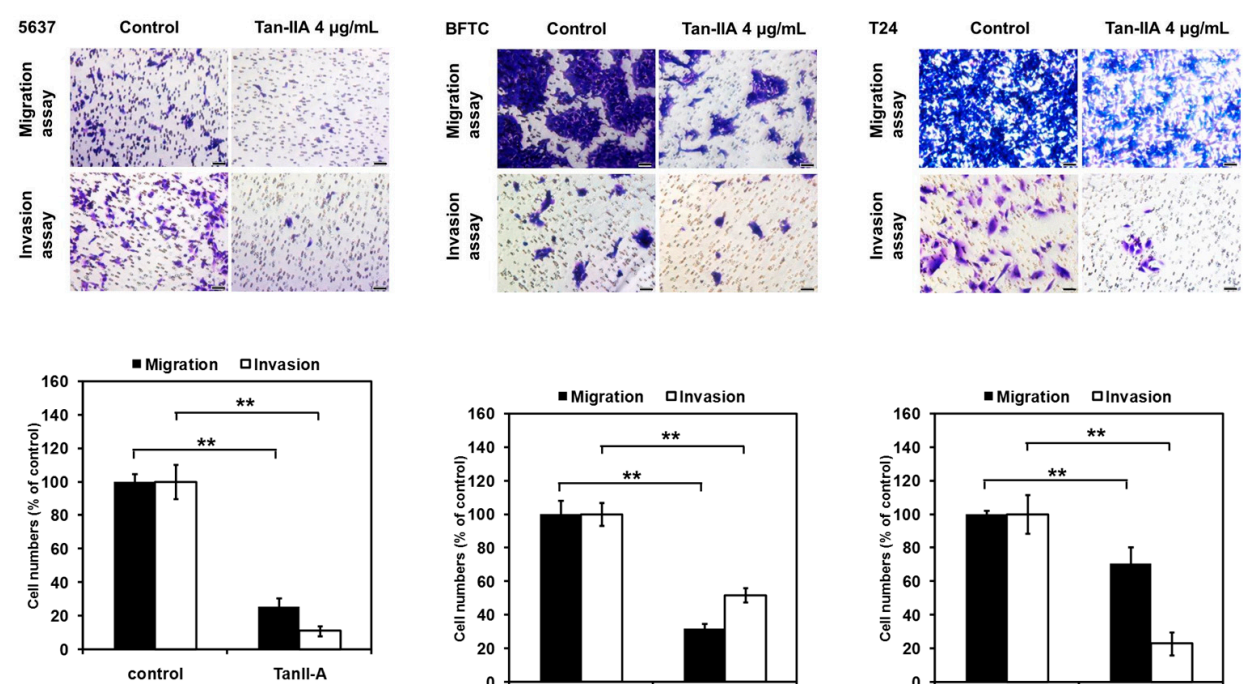

B

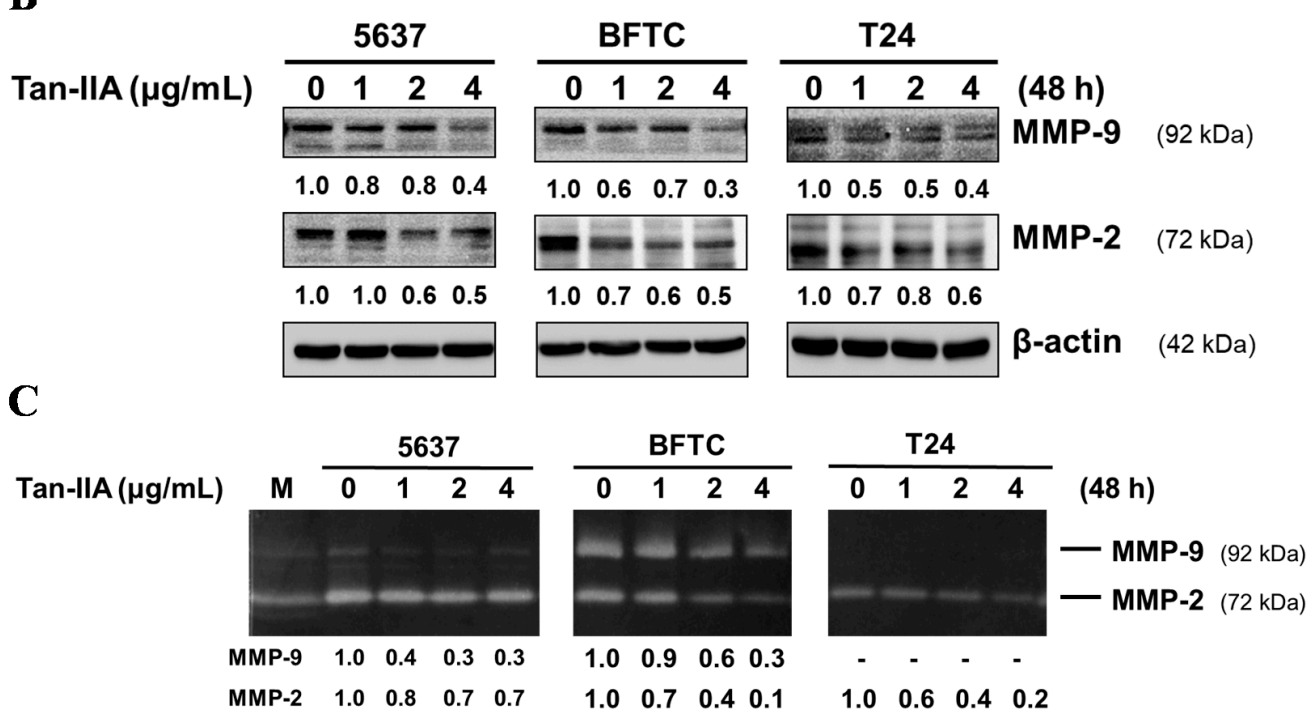

Figure 1. Tan-IIA inhibited migratory and invasive ability in human BCa cells. (A) Human BCa cells were treated with $0.2 \%$ DMSO as a vehicle control or $4 \mu \mathrm{g} / \mathrm{mL}$ Tan-IIA for $24 \mathrm{~h}$ and then seeded onto the transwell hanging insert for migration $(24 \mathrm{~h})$ and invasion $(48 \mathrm{~h})$ assays. Images were captured using an inverted microscope with $200 \times$ magnification; Scale bar: $50 \mu \mathrm{m}$. The migration and invasion of BCa cells were quantified by counting the stained cells that migrated into the underside of the hanging insert membrane; (B) human BCa cells were treated with different concentrations of Tan-IIA $(1,2$ and $4 \mu \mathrm{g} / \mathrm{mL})$ for $48 \mathrm{~h}$. The protein of total cell lysates were then used to detect MMP-9/-2 protein expression using western blot, and the (C) supernatant was used to detect the enzymatic activity using zymography analysis. M: marker. Data are presented as means \pm S.D. from three different experiments. ** $p<0.01$ versus vehicle.

Western blot results indicated Tan-IIA down-regulated the protein expression of MMP-9/-2 in a dose-dependent manner (Figure 1B). Zymography analysis also showed that Tan-IIA attenuated the enzymatic activity of MMP-9/-2 in a dose-dependent manner (Figure 1C). Taken together, these results suggested that Tan-IIA might be an effective inhibitor of cell migration and invasion of BCa cells. 


\subsection{Tan-IIA Inhibits EMT in Human BCa Cells}

EMT is a crucial step for the invasion and metastasis of BCa cells. We first show that Tan-IIA could inhibit cellular migration and invasion in BCa cells, and this is accompanied by the up-regulation of epithelial marker E-cadherin, the down-regulation of mesenchymal markers $\mathrm{N}$-cadherin and Vimentin, and the down-regulation of transcription factor Snail and Slug, at both the mRNA and protein level as evidenced by quantitative RT-PCR (qRT-PCR) (Figure 2A) and western blot (Figure 2B,C).

$\mathbf{A}$

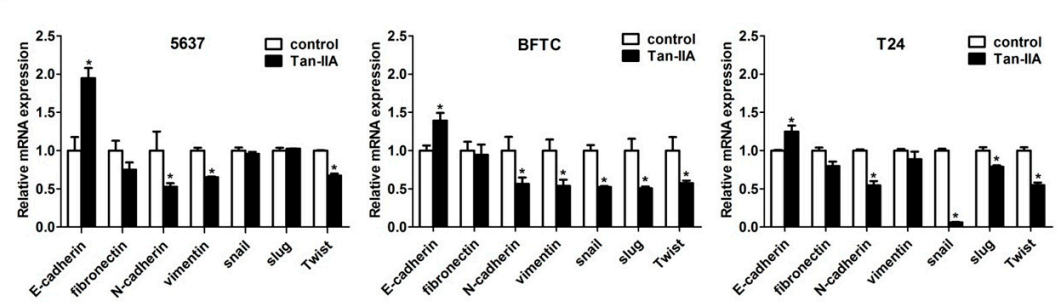

B

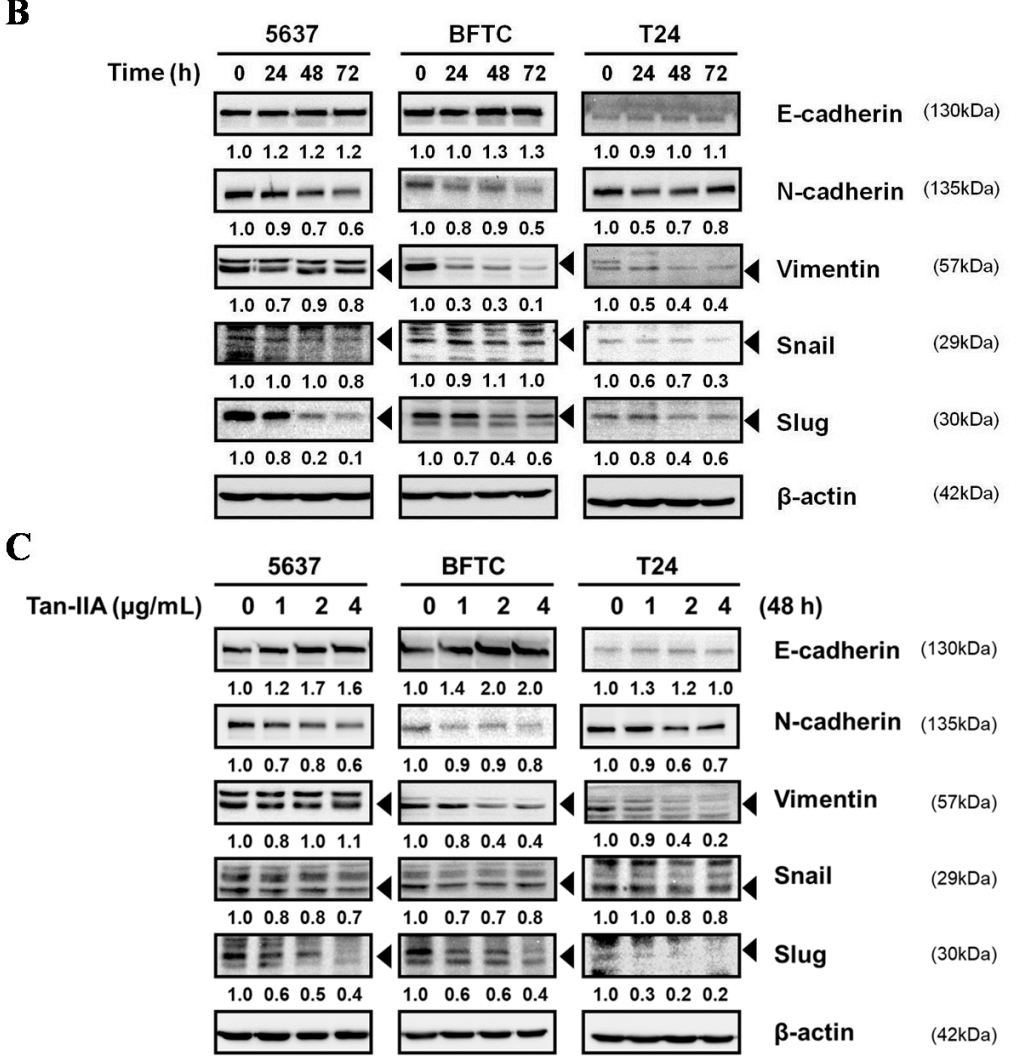

Figure 2. Tan-IIA inhibited EMT on human BCa cells. (A) Human BCa cells were treated with $4 \mu \mathrm{g} / \mathrm{mL}$ Tan-IIA for $24 \mathrm{~h}$. The expression of EMT-related genes was detected by qRT-PCR analysis; (B) human BCa cells were treated with $4 \mu \mathrm{g} / \mathrm{mL}$ Tan-IIA for 24 to $72 \mathrm{~h}$. The expressions of EMT-related genes were detected by western blot. (C) Human BCa cells were treated with increasing concentrations of Tan-IIA $(1,2$ and $4 \mu \mathrm{g} / \mathrm{mL})$ for $48 \mathrm{~h}$. The expressions of EMT-related genes were detected by western blot. Data are presented as means \pm S.D. from three different experiments. ${ }^{*} p<0.05$ versus vehicle.

\subsection{Tan-IIA Inhibits EMT via Down-Regulated CCL2 Expression in Human BCa Cells}

Previous reports suggested that high levels of CCL2 expression play a key role in BCa progression and metastasis in vitro and in vivo $[27,32,39]$. Thus, we analyzed the CCL2 expression in the culture medium of human BCa cells treated with or without Tan-IIA. As shown in Figure 3A, Tan-IIA inhibited the CCL2 expression in all BCa cell lines detected by PCR and qRT-PCR. Furthermore, ELISA tests 
confirmed that the protein level of CCL2 secreted by BCa cells was inhibited by Tan-IIA treatment in a dose-dependent manner (Figure 3B). These results showed that Tan-IIA down-regulated CCL2 expression in BCa cells.

$\mathbf{A}$
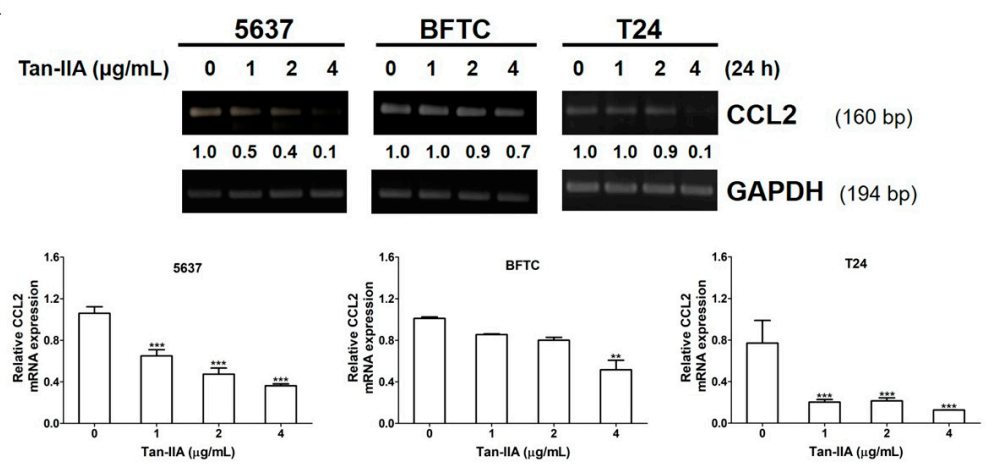

B
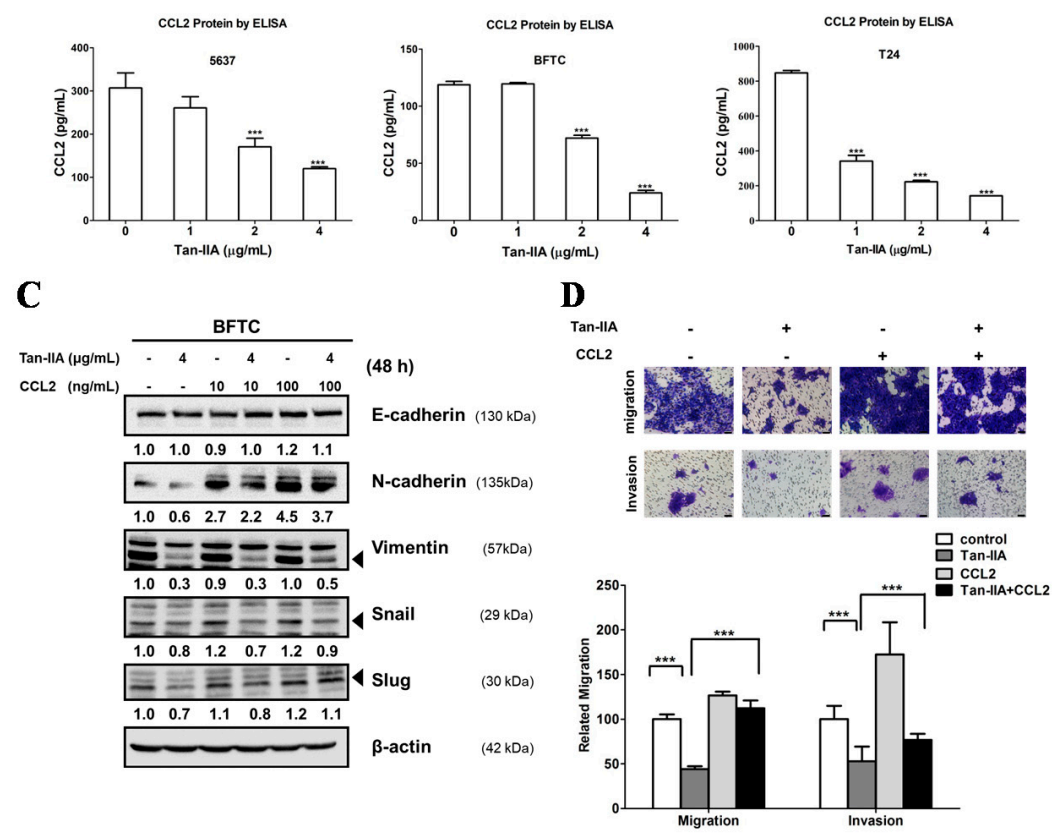

Figure 3. Tan-IIA inhibited the CCL2 expression and reversed the EMT in human BCa cells. (A) Human $\mathrm{BCa}$ cells were treated with increasing concentrations of Tan-IIA for $24 \mathrm{~h}$. The expression of CCL2 was detected by PCR and qRT-PCR; (B) Human BCa cells were treated with increasing concentrations of Tan-IIA for $48 \mathrm{~h}$. The supernatant was collected for CCL2 protein detection using ELISA assay; (C) BFTC cells were treated with or without $4 \mu \mathrm{g} / \mathrm{mL}$ Tan-IIA in the presence or absence of CCL2 recombinant protein for $48 \mathrm{~h}$. The EMT-related gene expression was detected by western blot; (D) BFTC cells were treated with or without $4 \mu \mathrm{g} / \mathrm{mL}$ Tan-IIA in the presence or absence of $100 \mathrm{ng} / \mathrm{mL}$ human CCL2 recombinant protein for $24 \mathrm{~h}$, followed by migration $(24 \mathrm{~h})$ or invasion $(48 \mathrm{~h})$ assays and analyzed as previous described. Data are presented as means \pm S.D. from three different experiments. ${ }^{* * *} p<0.001$ versus vehicle.

To investigate the mechanism by which Tan-IIA inhibits CCL2 resulting in metastatic inhibition, BFTC cells were treated with or without human CCL2 recombinant protein (10 or $100 \mathrm{ng} / \mathrm{mL})$ in the presence or absence of $4 \mu \mathrm{g} / \mathrm{mL}$ Tan-IIA for $48 \mathrm{~h}$ to examine the EMT-related genes expression. As shown in Figure 3C, treatment with CCL2 recombinant protein increased the expression of mesenchymal marker N-cadherin and Vimentin, along with transcription factor Snail and Slug, which were down-regulated by Tan-IIA treatment. In addition, treatment with CCL2 recombinant protein 
attenuated the inhibitory effect on migration and invasion induced by Tan-IIA treatment (Figure 3D). Together, these findings indicate that Tan-IIA inhibited EMT in BCa cells via the down-regulation of CCL2.

\subsection{Tan-IIA Inhibits STAT3-CCL2 Signaling in Human BCa Cells}

Recent studies indicated that CCL2 signaling plays a pivotal role in regulating STAT3 activation and EMT [40], and the inhibition of STAT3 signaling may reduce the invasiveness of BCa [41]. We further examined whether Tan-IIA could inhibit the activation of STAT3 on BCa cells. Human BCa cells were treated with Tan-IIA for indicated time points and p-STAT3 (Tyr705) was analyzed by western blot. As shown in Figure 4A,B, Tan-IIA inhibited the activation of STAT3 by decreasing the phosphorylation of STAT3 at Tyr705 in all BCa cell lines in a time- and dose-dependent manner. To elucidate the mechanism by which Tan-IIA inhibits CCL2 through regulating STAT3, BFTC cells were transfected with the STAT3 siRNA and the expression of STAT3 and CCL2 were examined by western blot. Silencing the expression of STAT3 leads to the inhibition of CCL2 expression (Figure 4C). However, treatment with human CCL2 recombinant protein $(10$ or $100 \mathrm{ng} / \mathrm{mL})$ cannot restore the regulation of STAT3 via phosphorylation of Tyr705, and this was inhibited by Tan-IIA treatment. These results suggested that Tan-IIA down-regulated the CCL2 expression via inhibition of the STAT3 pathway in human BCa cells.

\section{(A)}

(B)
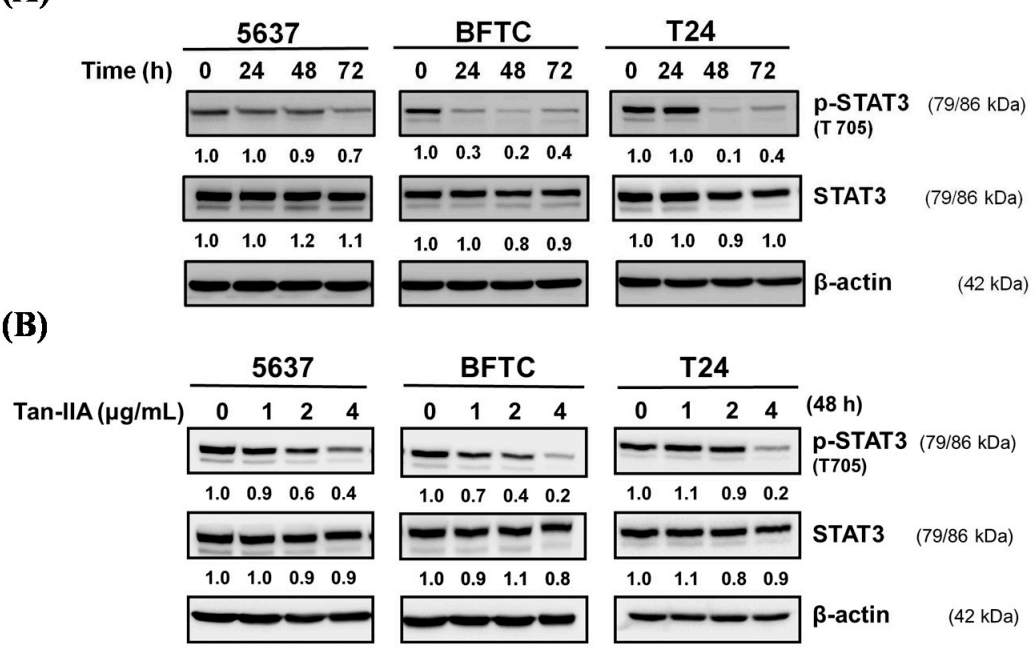

(C)

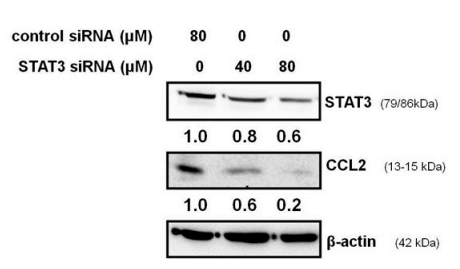

(D)

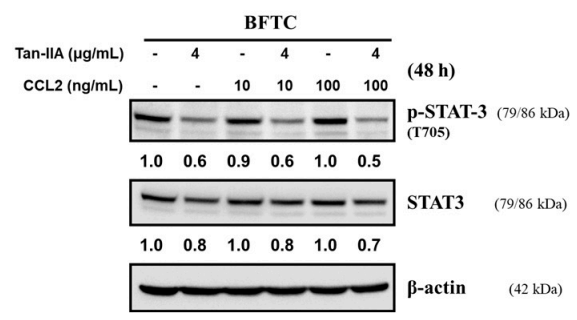

Figure 4. Tan-IIA inhibited STAT3-CCL2 signaling in human BCa cells. (A) Human BCa cells were treated with $4 \mu \mathrm{g} / \mathrm{mL}$ Tan-IIA for indicated time points, and the expression of phospho-STAT3 (T705) was detected by western blot; (B) human BCa cells were treated with increasing concentrations of Tan-IIA for $48 \mathrm{~h}$, the expression of phospho-STAT3 (T705) were detected by western blot; (C) BFTC cells were transfected with control or STAT3 siRNA for $24 \mathrm{~h}$, and the expression of STAT3 and CCL2 was detected by western blot; (D) BFTC cells were treated with or without $4 \mu \mathrm{g} / \mathrm{mL}$ Tan-IIA in the presence or absence of human CCL2 recombinant protein for $48 \mathrm{~h}$. The expression of phospho-STAT3 (T705) and STAT3 was detected by western blot. 


\section{Discussion}

Our previous study reported that Tan-IIA could inhibit the proliferation and migration of human BCa cells [25], but the underlying mechanism of Tan-IIA attenuating the migration and invasion of BCa cells remains unclear. EMT is a process by which epithelial cells gradually transform into mesenchymal-like cells to promote the migration and invasiveness of cancer cells [42]. Our results showed that Tan-IIA treatment could inhibit the process of EMT as evidenced by increased level of the epithelial marker E-cadherin and decreased level of mesenchymal markers ( $\mathrm{N}$-cadherin and Vimentin). Activation of MMP proteins leads to cell migration and penetration to the basement membrane, playing an important role in EMT processes [43]. In previous studies, Tan-IIA decreased migration or invasion through inhibiting MMP-9/-2 secretion in gastric cancer and osteosarcoma [11,18]. Similar results observed in our study showed that Tan-IIA suppressed both the protein expression and enzymatic activity of MMP-9/-2 on human BCa cells (Figure 1B). Together, these findings suggest that Tan-IIA inhibits EMT in human BCa cells.

Several reports have demonstrated the importance of CCL2 and EMT signals in BCa progression. Chiu et al. reported that blocking the CCL2/CCR2 pathway could decrease the migration and invasion of BCa cells [39]. Additional reports show that CCL2 signals promote EMT in various tumors including BCa $[32,40,44,45]$. The present study provides evidence that Tan-IIA decreased CCL2 expression in a dose-dependent manner by qRT-PCR and ELISA analysis (Figure 3). The addition of CCL2 recombinant protein resulted in a partial reversal of EMT markers, and attenuated the Tan-IIA-induced migration and invasion inhibition in BCa cells. Our results show that Tan-IIA inhibits the EMT in BCa cells via the suppression of CCL2 expression.

Additional reported data suggested that CCL2 induced EMT through the activation of STAT3 signals $[33,40]$ and inhibited STAT3 signaling to reduce the invasiveness of tumor cells $[41,46]$. Our data showed that Tan-IIA could inhibit the p-STAT3 (Tyr705) in a time- and dose-dependent manner. Besides, inhibition of STAT3 expression by STAT3 siRNA transfection attenuated the expression of CCL2. The phosphorylation of STAT3, inhibited by Tan-IIA, cannot be restored by CCL2 recombinant protein addition. These data suggested that Tan-IIA inhibits EMT of human BCa cells via modulation of STAT3-CCL2 signaling (Figure 5). Several effects of Tan-IIA on human cancer were also integrated to get a better view of possible anti-cancerogenic effects of Tan-IIA [47-50]. In addition, since the results from this study were based on in vitro assays of human $\mathrm{BCa}$ cells, the in vivo experiments are necessary for future study.

EMT is orchestrated by several signaling pathways, including JAK/STAT3 and TGF- $\beta /$ Smad signaling. Recent studies have demonstrated that TGF- $\beta$-mediated cancer metastasis was associated with the activation of STAT3 pathway in colorectal and lung cancer [51,52]. STAT3 activation can increase smad7 expression and form an inhibitory complex with smad3 which eventually suppress EMT [53]. Recent study elucidated the mechanisms behind the tumoricidal activity of TCM clinical prescription Jianpi Huayu Decoction (JHD) in Hepatocellular carcinoma (HCC) treatment. Their results indicated that Tan-IIA might be the one of crucial components of the JHD that targets on the TGF- $\beta$ /Smad3 pathway and inhibits EMT [50]. Taken together, the targeted blockade of the STAT3/smad3 axis in tumor cells may be an effective therapeutic strategy against tumor metastatic progression and worth for further investigation. 


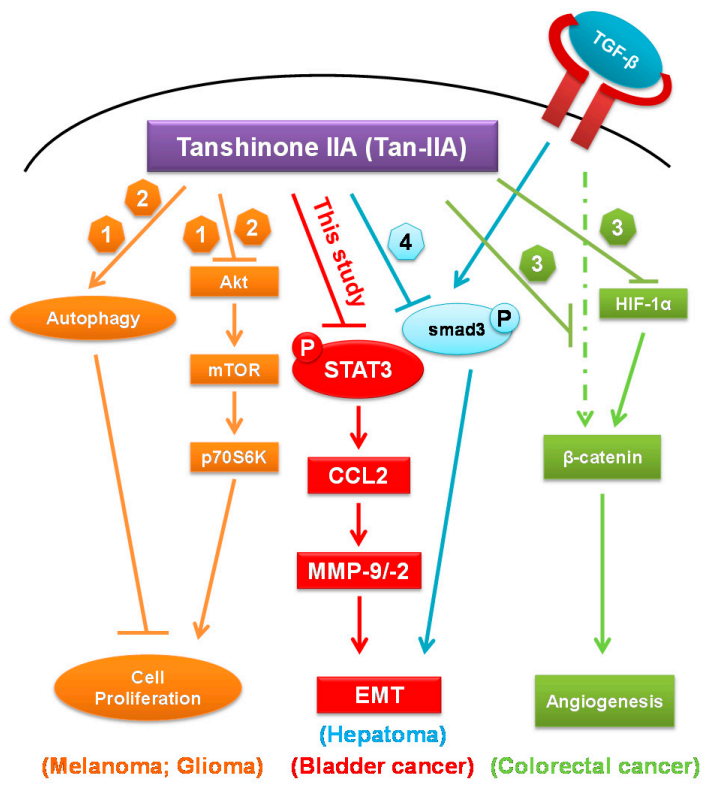

Figure 5. Schematic representation the anti-cancerogenic roles of Tan-IIA. CCL2: Chemokine (C-C motif) ligand 2; EMT: Epithelial-Mesenchymal Transition; HIF-1 $\alpha$ : Hypoxia-inducible factor- $1 \alpha$; MMP: Matrix MetalloProteinases; mTOR: mammalian target of rapamycin; P: phosphorylation; p70S6K: p70 ribosomal protein S6 kinase; STAT3: signal transducer and activator of transcription 3; Tan-IIA: Tanshinone IIA; TGF- $\beta$ : transforming growth factor $\beta . \downarrow$ : stimulatory modification; $\perp$ : inhibitory modification; Dashed arrow: putative stimulatory modification [47-50].

\section{Materials and Methods}

\subsection{Chemicals and Antibodies}

Tanshinone IIA $\left(\mathrm{C}_{19} \mathrm{H}_{18} \mathrm{O}_{3},>97 \%\right.$ HPLC), Dimethyl sulfoxide (DMSO), [3-(4,5-dimethyl thizol-2-yl)-2,5-diphenyl tetrazolium bromide] (MTT), Tween-20, methanol, and horseradish peroxidase-conjugated secondary antibodies were purchased from Sigma Chemical Co. (St. Louis, MO, USA). The antibodies against p-STAT3 (Tyr705), STAT3, E-cadherin, N-cadherin, Vimentin, Slug, Snail, MMP-2, MMP-9 and $\beta$-actin were all purchased from Cell Signaling Technology, Inc., (Danvers, MA, USA). The human CCL2 recombinant protein was purchased from Santa Cruz Biotechnology, Inc. (Dallas, TX, USA). Polyvinyldenefluoride (PVDF) membranes, BSA protein assay kit and western blot chemiluminescence reagent were purchased from Amersham Biosciences (Arlington Heights, IL, USA).

\subsection{Cell Culture}

The human BCa cell lines 5637 (grade II carcinoma), BFTC (BFTC 905, papillary transitional cell carcinoma), and T24 (transitional cell carcinoma) were purchased from BCRC (Bioresource Collection and Research Center, Hsinchu, Taiwan). Cells were cultured in appropriate medium supplemented with $10 \% \mathrm{FBS}, 100 \mathrm{U} / \mathrm{mL}$ penicillin and $100 \mathrm{U} / \mathrm{mL}$ streptomycin (all from Invitrogen, Carlsbad, CA, USA) at $37^{\circ} \mathrm{C}$ in a humidified atmosphere with $5 \% \mathrm{CO}_{2}$.

\subsection{Western Blot Analysis}

Five hundred thousand cells per 6-cm plate were lysed with $200 \mu \mathrm{L}$ M-PER mammalian protein extraction reagent containing protease inhibitor cocktail (Thermo Scientific, Rockford, IL, USA) and centrifuged at $13,000 \times \mathrm{g}$ at $4{ }^{\circ} \mathrm{C}$ for $10 \mathrm{~min}$. The protein concentration in the supernatants was quantified using a BSA Protein Assay Kit. Electrophoresis was performed on a NuPAGE Bis-Tris Electrophoresis System using $20 \mu \mathrm{g}$ of reduced protein extract per lane. Resolved proteins were 
transferred to PVDF membranes, blocked with 5\% skim milk for $1 \mathrm{~h}$ at room temperature, finally probed with the specific primary antibodies at $4{ }^{\circ} \mathrm{C}$ overnight. After the PVDF membrane was washed three times with TBS $/ 0.2 \%$ Tween- 20 at room temperature, it was incubated with appropriate secondary antibody labeled with horseradish peroxidase (Sigma Chemical, St. Louis, MO, USA) for $1 \mathrm{~h}$ at room temperature. All resolved proteins bands were detected using Western Lightning ${ }^{\mathrm{TM}}$ Chemiluminescence Reagent Plus (Amersham Biosciences, Arlington Heights, IL, USA).

\subsection{Cell Migration and Invasion Assay}

The trans-well assay was performed using Hanging inserts (Millipore Co., Billerica, MA, USA) with $8 \mu \mathrm{m}$ polycarbonate membrane in a 24-well plate. Cells were seeded in 6 well plates and treated without or with $4 \mu \mathrm{g} / \mathrm{mL}$ Tan-IIA with or without CCL2 for $24 \mathrm{~h}$. Cells were then detached and seeded $\left(5 \times 10^{4}\right)$ to the upper chamber of the transwell plates. Upper chambers were filled with serum free medium and lower chambers were filled with cultured medium containing $10 \% \mathrm{FBS}$ as a chemo-attractant. Incubation was carried out at $37^{\circ} \mathrm{C}$ for the indicated $24 \mathrm{~h}$. The hanging inserts were washed with PBS, and cells on the upper filter surface were wiped away with a cotton swab. The inserts were subsequently fixed with $10 \%$ formalin for $10 \mathrm{~min}$ at room temperature, stained with $0.2 \% w / v$ crystal violet, washed with PBS, the remaining cells were counted on the opposite site of the filter under a light microscope operating at $200 \times$ magnification. The migration cell numbers of control group were considered as $100 \%$. For the invasion assay, a Matrigel basement membrane matrix (BD Biosciences, San Jose, CA, USA) was coated to the upper side of the hanging inserts at a concentration of $2 \mathrm{mg} / \mathrm{mL}$. Cells were seeded onto the coated hanging inserts and followed by migration assay protocol.

\subsection{RNA Extraction and Real-Time RT-PCR}

Total RNA was extracted from cell lines using RNeasy Mini Kit ${ }^{\circledR}$ (Qiagen, Valencia, CA, USA) and reverse transcribed at $37^{\circ} \mathrm{C}$ for 60 min with Omniscript RT Kit ${ }^{\circledR}$ (Qiagen) according to the manufacturer's instructions. Real-time RT-PCR analysis was performed in triplicate in a Step One Plus Real-Time PCR system (Applied Biosystems, Foster City, CA, USA) with Power SYBR ${ }^{\circledR}$ Green PCR Master Mix (Applied Biosystems) in a final volume of $20 \mu \mathrm{L} /$ reaction. Threshold cycle $\left(C_{t}\right)$ value of each tested gene was normalized to the $C_{t}$ value of the GAPDH control from the same RNA preparation. The ratio of transcription of each gene was calculated as $2^{-(\Delta C t)}$, where $\Delta C_{t}$ is the difference $C_{t}$ (test gene $)-C_{t}(G A P D H)$. Real-time RT-PCR primer sequences used in this study are listed in Table 1.

Table 1. The gene-specific primers used in this study.

\begin{tabular}{|c|c|}
\hline Gene & Primers \\
\hline CCL2 & $\begin{array}{l}\text { sense: } 5^{\prime} \text {-GATCTCAGTGCAGAGGCTCG-3' } \\
\text { antisense: } \text { 5'-TGCTTGTCCAGGTGGTCCAT-3 }^{\prime}\end{array}$ \\
\hline E-cadherin & $\begin{array}{l}\text { sense: 5'-ACGTCGTAATCACCACACTGA-3' } \\
\text { antisense: } 5^{\prime} \text {-TTCGTCACTGCTACGTGTAGAA-3' }\end{array}$ \\
\hline$N$-cadherin & $\begin{array}{l}\text { sense: } 5^{\prime} \text {-ACAGTGGCCACCTACAAAGG-3' } \\
\text { antisense: 5'-CCGAGATGGGGTTGATAATG-3' }\end{array}$ \\
\hline Fibronectin & $\begin{array}{l}\text { sense: } 5^{\prime} \text {-CCCACCGTCTCAACATGCTTAG-3' } \\
\text { antisense: } 5^{\prime} \text {-CTCGGCTTCCTCCATAACAAGTAC-3' }\end{array}$ \\
\hline Vimentin & $\begin{array}{l}\text { sense: } 5^{\prime} \text {-CTTCGCCAACTACATCGACA-3' } \\
\text { antisense: 5'-GCTTCAACGGCAAAGTTCTC-3' }\end{array}$ \\
\hline Snail & $\begin{array}{l}\text { sense: } 5^{\prime} \text {-TCGTCCTTCTCCTCTACTTC-3' } \\
\text { antisense: } 5^{\prime} \text {-TTCCTTGTTGCAGTATTTGC-3' }\end{array}$ \\
\hline Slug & $\begin{array}{l}\text { sense: } 5^{\prime} \text {-TGTTGCAGTGAGGGCAAGAA-3' } \\
\text { antisense: } 5^{\prime} \text {-GACCCTGGTTGCTTCAAGGA-3' }\end{array}$ \\
\hline GAPDH & $\begin{array}{c}\text { sense: } 5^{\prime} \text {-CCATGGAGAAGGCTGGGG-3' } \\
\text { antisense: } 5^{\prime} \text {-CAAAGTTGTCATGGATGACC-3' }\end{array}$ \\
\hline
\end{tabular}




\subsection{Enzyme-Linked Immunosorbent Assay (ELISA)}

Human MCP-1/CCL2 ELISA kit was purchased from R\&D Systems. BCa cells were cultured in serum-free medium with or without Tan-IIA for $72 \mathrm{~h}$. The medium were collected $(400 \mu \mathrm{L} / \mathrm{sample}$ in 96-well) for ELISA assay according to manufacturer's instructions.

\subsection{Gelatin Zymography}

The BCa cells were cultured in serum-free medium containing Tan-IIA $(0,1,2,4 \mu \mathrm{g} / \mathrm{mL})$ for $48 \mathrm{~h}$ and the supernatant was collected. The supernatant was mixed with non-reducing SDS gel sample buffer. Electrophoresis was carried out using 10\% native polyacrylamide gel containing $0.1 \%$ gelatin (Sigma, St. Louis, MO, USA) on a NuPAGE Bis-Tris Electrophoresis System. After electrophoresis, the gels were washed in wash buffer containing $2.5 \%$ Triton X-100 at room temperature, and then incubated with the reaction buffer containing $1 \mathrm{M} \mathrm{CaC1}_{2}, 2 \% \mathrm{NaN}_{3}, 1 \mathrm{M}$ Tris- $\mathrm{HCl}(\mathrm{pH} 8.0)$ at $37^{\circ} \mathrm{C}$ overnight. Gels were stained by Coomassie Brilliant Blue R-250 solution and gelatinolytic activity was shown as clear areas in the gel.

\subsection{Small Interfering RNA (siRNA) Transfection}

STAT3 siRNA (\#6582) was purchased from Cell Signaling Technology, Inc., (Danvers, MA, USA). Non-targeting siRNA (ON-TARGET plus non-targeting pool) were purchased from Dharmacon RNAi Technologies (Lafayette, CO, USA). Non-targeting control sequences were not provided. BFTC cells at $50-60 \%$ confluence were transfected with siRNA (40 or $80 \mathrm{nM}$ ) using the DharmaFECT 4 transfection reagents (GE Healthcare Dharmacon, Lafayette, CO, USA) according to the manufacturer's protocol. Cells were cultured for $24 \mathrm{~h}$, and then treated with Tan-IIA or vehicle for an additional $48 \mathrm{~h}$. Proteins were then isolated for western blotting.

\subsection{Statistical Analysis}

All data were shown as mean \pm S.D. Statistical differences were analyzed using the Student's $t$-test for normally distributed values.

\section{Conclusions}

In conclusion, our study demonstrated that Tan-IIA inhibits EMT in human BCa cells. The anti-metastatic effects of Tan-IIA in human BCa cells were shown by migration and invasion assay. Tan-IIA is shown to regulate EMT-related gene expression via the suppression of CCL2. The inhibition of CCL2 might be linked to the phosphorylation inhibition at Tyr705 of STAT3 by Tan-IIA. Tan-IIA has been shown to inhibit EMT in human BCa cells, and the mechanism involved was mediated through the modulation of STAT3-CCL2 signaling. Thus, our findings suggest a novel role of Tan-IIA in controlling BCa, suggesting that Tan-IIA might be a potential option for treating BCa metastasis.

Acknowledgments: This work was supported by grants from the Taichung Tzu Chi Hospital, Buddhist Tzu Chi Medical Foundation, Taichung, Taiwan (TTCRD104-10, TTCRD104-19, TTCRD105-17, TTCRD105-20). The funders had no role in study design, data collection and analysis, decision to publish, or preparation of the manuscript.

Author Contributions: Sung-Ying Huang and Sheng-Chun Chiu conceived and designed the experiments; Sung-Ying Huang, Sheng-Chun Chiu and Shu-Fang Chang performed the experiments; Sheng-Chun Chiu and Shu-Fang Chang analyzed the data; Sung-Ying Huang, Sheng-Chun Chiu and Kuan-Fu Liao contributed reagents/materials/analysis tools; Sung-Ying Huang, Sheng-Chun Chiu, Shu-Fang Chang and Kuan-Fu Liao wrote the paper.

Conflicts of Interest: The authors declare no conflict interests. 


\section{Abbreviations}

$\begin{array}{ll}\text { CCL2 } & \text { Chemokine (C-C motif) ligand 2 } \\ \text { EMT } & \text { Epithelial-mesenchymal transition } \\ \text { MMP } & \text { Matrix metalloproteinases } \\ \text { STAT3 } & \text { Signal transducer and activator of transcription 3 } \\ \text { Tan-IIA } & \text { Tanshinone IIA }\end{array}$

\section{References}

1. Siegel, R.L.; Miller, K.D.; Jemal, A. Cancer statistics, 2016. CA Cancer J. Clin. 2016, 66, 7-30. [CrossRef] [PubMed]

2. Antoni, S.; Ferlay, J.; Soerjomataram, I.; Znaor, A.; Jemal, A.; Bray, F. Bladder cancer incidence and mortality: A global overview and recent trends. Eur. Urol. 2017, 71, 96-108. [CrossRef] [PubMed]

3. Jemal, A.; Siegel, R.; Ward, E.; Hao, Y.; Xu, J.; Murray, T.; Thun, M.J. Cancer statistics, 2008. CA Cancer J. Clin. 2008, 58, 71-96. [CrossRef] [PubMed]

4. Lutzeyer, W.; Rubben, H.; Dahm, H. Prognostic parameters in superficial bladder cancer: An analysis of 315 cases. J. Urol. 1982, 127, 250-252. [CrossRef]

5. Wu, X.R. Urothelial tumorigenesis: a tale of divergent pathways. Nat. Rev. Cancer 2005, 5, 713-725. [CrossRef] [PubMed]

6. Che, A.J.; Zhang, J.Y.; Li, C.H.; Chen, X.F.; Hu, Z.D.; Chen, X.G. Separation and determination of active components in Radix Salviae miltiorrhizae and its medicinal preparations by nonaqueous capillary electrophoresis. J. Sep. Sci. 2004, 27, 569-575. [PubMed]

7. Zhou, L.; Zuo, Z.; Chow, M.S. Danshen: An overview of its chemistry, pharmacology, pharmacokinetics, and clinical use. J. Clin. Pharmacol. 2005, 45, 1345-1359. [CrossRef] [PubMed]

8. Wei, B.; You, M.G.; Ling, J.J.; Wei, L.L.; Wang, K.; Li, W.W.; Chen, T.; Du, Q.M.; Ji, H. Regulation of antioxidant system, lipids and fatty acid $\beta$-oxidation contributes to the cardioprotective effect of sodium tanshinone IIA sulphonate in isoproterenol-induced myocardial infarction in rats. Atherosclerosis 2013, 230, 148-156. [CrossRef] [PubMed]

9. Fan, G.; Jiang, X.; Wu, X.; Fordjour, P.A.; Miao, L.; Zhang, H.; Zhu, Y.; Gao, X. Anti-Inflammatory Activity of Tanshinone IIA in LPS-Stimulated RAW264.7 Macrophages via miRNAs and TLR4-NF-kB Pathway. Inflammation 2016, 39, 375-384. [CrossRef] [PubMed]

10. Huang, S.T.; Huang, C.C.; Huang, W.L.; Lin, T.K.; Liao, P.L.; Wang, P.W.; Liou, C.W.; Chuang, J.H. Tanshinone IIA induces intrinsic apoptosis in osteosarcoma cells both in vivo and in vitro associated with mitochondrial dysfunction. Sci. Rep. 2017, 7, 40382. [CrossRef] [PubMed]

11. Su, C.C. Tanshinone IIA decreases the migratory ability of AGS cells by decreasing the protein expression of matrix metalloproteinases, nuclear factor кB-p65 and cyclooxygenase-2. Mol. Med. Rep. 2016, 13, 1263-1268. [PubMed]

12. Xie, J.; Liu, J.; Liu, H.; Liang, S.; Lin, M.; Gu, Y.; Liu, T.; Wang, D.; Ge, H.; Mo, S.L. The antitumor effect of tanshinone IIA on anti-proliferation and decreasing VEGF/VEGFR2 expression on the human non-small cell lung cancer A549 cell line. Acta Pharm. Sin. B 2015, 5, 554-563. [CrossRef] [PubMed]

13. Wang, J.F.; Feng, J.G.; Han, J.; Zhang, B.B.; Mao, W.M. The molecular mechanisms of Tanshinone IIA on the apoptosis and arrest of human esophageal carcinoma cells. BioMed Res. Int. 2014, 2014. [CrossRef] [PubMed]

14. Chiu, S.C.; Huang, S.Y.; Chen, S.P.; Su, C.C.; Chiu, T.L.; Pang, C.Y. Tanshinone IIA inhibits human prostate cancer cells growth by induction of endoplasmic reticulum stress in vitro and in vivo. Prostate Cancer Prostatic Dis. 2013, 16, 315-322. [CrossRef] [PubMed]

15. Tsai, M.Y.; Yang, R.C.; Wu, H.T.; Pang, J.H.; Huang, S.T. Anti-angiogenic effect of Tanshinone IIA involves inhibition of matrix invasion and modification of MMP-2/TIMP-2 secretion in vascular endothelial cells. Cancer Lett. 2011, 310, 198-206. [CrossRef] [PubMed]

16. Wu, W.Y.; Yan, H.; Wang, X.B.; Gui, Y.Z.; Gao, F.; Tang, X.L.; Qin, Y.L.; Su, M.; Chen, T.; Wang, Y.P. Sodium tanshinone IIA silate inhibits high glucose-induced vascular smooth muscle cell proliferation and migration through activation of AMP-activated protein kinase. PLoS ONE 2014, 9, e94957. [CrossRef] [PubMed] 
17. Yun, S.M.; Jung, J.H.; Jeong, S.J.; Sohn, E.J.; Kim, B.; Kim, S.H. Tanshinone IIA induces autophagic cell death via activation of AMPK and ERK and inhibition of mTOR and p70 S6K in KBM-5 leukemia cells. Phytother. Res. 2014, 28, 458-464. [CrossRef] [PubMed]

18. Zhang, Y.; Wei, R.X.; Zhu, X.B.; Cai, L.; Jin, W.; Hu, H. Tanshinone IIA induces apoptosis and inhibits the proliferation, migration, and invasion of the osteosarcoma MG-63 cell line in vitro. Anticancer Drugs 2012, 23, 212-219. [CrossRef] [PubMed]

19. Zhu, Y.Q.; Wang, B.Y.; Wu, F.; An, Y.K.; Zhou, X.Q. Influence of tanshinone IIA on the apoptosis of human esophageal Ec-109 cells. Nat. Prod. Commun. 2016, 11, 17-19. [PubMed]

20. Zhang, J.; Wang, J.; Jiang, J.Y.; Liu, S.D.; Fu, K.; Liu, H.Y. Tanshinone IIA induces cytochrome c-mediated caspase cascade apoptosis in A549 human lung cancer cells via the JNK pathway. Int. J. Oncol. 2014, 45, 683-690. [PubMed]

21. Tseng, P.Y.; Lu, W.C.; Hsieh, M.J.; Chien, S.Y.; Chen, M.K. Tanshinone IIA induces apoptosis in human oral cancer KB cells through a mitochondria-dependent pathway. BioMed Res. Int. 2014, 2014, 540516. [CrossRef] [PubMed]

22. Gong, Y.; Li, Y.; Lu, Y.; Li, L.; Abdolmaleky, H.; Blackburn, G.L.; Zhou, J.R. Bioactive tanshinones in Salvia miltiorrhiza inhibit the growth of prostate cancer cells in vitro and in mice. Int. J. Cancer 2011, 129, 1042-1052. [CrossRef] [PubMed]

23. Gong, Y.; Li, Y.; Abdolmaleky, H.M.; Li, L.; Zhou, J.R. Tanshinones inhibit the growth of breast cancer cells through epigenetic modification of aurora a expression and function. PLoS ONE 2012, 7, e33656. [CrossRef] [PubMed]

24. Liu, F.; Yu, G.; Wang, G.; Liu, H.; Wu, X.; Wang, Q.; Liu, M.; Liao, K.; Wu, M.; Cheng, X.; et al. An NQO1-initiated and p53-independent apoptotic pathway determines the anti-tumor effect of tanshinone IIA against non-small cell lung cancer. PLoS ONE 2012, 7, e42138. [CrossRef] [PubMed]

25. Chiu, S.C.; Huang, S.Y.; Chang, S.F.; Chen, S.P.; Chen, C.C.; Lin, T.H.; Liu, H.H.; Tsai, T.H.; Lee, S.S.; Pang, C.Y.; et al. Potential therapeutic roles of tanshinone IIA in human bladder cancer cells. Int. J. Mol. Sci. 2014, 15, 15622-15637. [CrossRef] [PubMed]

26. Vazquez-Lavista, L.G.; Lima, G.; Gabilondo, F.; Llorente, L. Genetic association of monocyte chemoattractant protein 1 (MCP-1)-2518 polymorphism in Mexican patients with transitional cell carcinoma of the bladder. Urology 2009, 74, 414-418. [CrossRef] [PubMed]

27. Amann, B.; Perabo, F.G.; Wirger, A.; Hugenschmidt, H.; Schultze-Seemann, W. Urinary levels of monocyte chemo-attractant protein-1 correlate with tumour stage and grade in patients with bladder cancer. Br. J. Urol. 1998, 82, 118-121. [CrossRef] [PubMed]

28. Brana, I.; Calles, A.; LoRusso, P.M.; Yee, L.K.; Puchalski, T.A.; Seetharam, S.; Zhong, B.; de Boer, C.J.; Tabernero, J.; Calvo, E. Carlumab, an anti-C-C chemokine ligand 2 monoclonal antibody, in combination with four chemotherapy regimens for the treatment of patients with solid tumors: An open-label, multicenter phase 1b study. Target Oncol. 2015, 10, 111-123. [CrossRef] [PubMed]

29. Mitchem, J.B.; Brennan, D.J.; Knolhoff, B.L.; Belt, B.A.; Zhu, Y.; Sanford, D.E.; Belaygorod, L.; Carpenter, D.; Collins, L.; Piwnica-Worms, D.; et al. Targeting tumor-infiltrating macrophages decreases tumor-initiating cells, relieves immunosuppression, and improves chemotherapeutic responses. Cancer Res. 2013, 73, 1128-1141. [CrossRef] [PubMed]

30. Mitchem, J.B.; DeNardo, D.G. Battle over CCL2 for control of the metastatic niche: neutrophils versus monocytes. Breast Cancer Res. 2012, 14, 315. [CrossRef] [PubMed]

31. Lee, C.C.; Ho, H.C.; Su, Y.C.; Lee, M.S.; Hung, S.K.; Lin, C.H. MCP1-Induced Epithelial-Mesenchymal Transition in Head and Neck Cancer by AKT Activation. Anticancer Res. 2015, 35, 3299-3306. [PubMed]

32. Rao, Q.; Chen, Y.; Yeh, C.R.; Ding, J.; Li, L.; Chang, C.; Yeh, S. Recruited mast cells in the tumor microenvironment enhance bladder cancer metastasis via modulation of ER $\beta / C C L 2 / C C R 2$ EMT/MMP9 signals. Oncotarget 2016, 7, 7842-7855. [CrossRef] [PubMed]

33. Chen, W.; Gao, Q.; Han, S.; Pan, F.; Fan, W. The CCL2/CCR2 axis enhances IL-6-induced epithelial-mesenchymal transition by cooperatively activating STAT3-Twist signaling. Tumor Biol. 2015, 36, 973-981. [CrossRef] [PubMed] 
34. Hsu, Y.L.; Hung, J.Y.; Tsai, Y.M.; Tsai, E.M.; Huang, M.S.; Hou, M.F.; Kuo, P.L. 6-shogaol, an active constituent of dietary ginger, impairs cancer development and lung metastasis by inhibiting the secretion of CC-chemokine ligand 2 (CCL2) in tumor-associated dendritic cells. J. Agric. Food Chem. 2015, 63, 1730-1738. [CrossRef] [PubMed]

35. Kortylewski, M.; Yu, H. Stat3 as a potential target for cancer immunotherapy. J. Immunother. 2007, 30, 131-139. [CrossRef] [PubMed]

36. Yu, H.; Pardoll, D.; Jove, R. STATs in cancer inflammation and immunity: A leading role for STAT3. Nat. Rev. Cancer 2009, 9, 798-809. [CrossRef] [PubMed]

37. Chen, C.L.; Cen, L.; Kohout, J.; Hutzen, B.; Chan, C.; Hsieh, F.C.; Loy, A.; Huang, V.; Cheng, G.; Lin, J. Signal transducer and activator of transcription 3 activation is associated with bladder cancer cell growth and survival. Mol. Cancer 2008, 7, 78. [CrossRef] [PubMed]

38. Yang, C.; Zhang, W.; Wang, L.; Kazobinka, G.; Han, X.; Li, B.; Hou, T. Musashi-2 promotes migration and invasion in bladder cancer via activation of the JAK2/STAT3 pathway. Lab. Investig. 2016, 96, 950-958. [CrossRef] [PubMed]

39. Chiu, H.Y.; Sun, K.H.; Chen, S.Y.; Wang, H.H.; Lee, M.Y.; Tsou, Y.C.; Jwo, S.C.; Sun, G.H.; Tang, S.J. Autocrine CCL2 promotes cell migration and invasion via PKC activation and tyrosine phosphorylation of paxillin in bladder cancer cells. Cytokine 2012, 59, 423-432. [CrossRef] [PubMed]

40. Izumi, K.; Fang, L.Y.; Mizokami, A.; Namiki, M.; Li, L.; Lin, W.J.; Chang, C. Targeting the androgen receptor with siRNA promotes prostate cancer metastasis through enhanced macrophage recruitment via CCL2/CCR2-induced STAT3 activation. EMBO Mol. Med. 2013, 5, 1383-1401. [CrossRef] [PubMed]

41. Sun, Y.; Cheng, M.K.; Griffiths, T.R.; Mellon, J.K.; Kai, B.; Kriajevska, M.; Manson, M.M. Inhibition of STAT signalling in bladder cancer by diindolylmethane: Relevance to cell adhesion, migration and proliferation. Curr. Cancer Drug Targets 2013, 13, 57-68. [CrossRef] [PubMed]

42. Sung, W.J.; Kim, H.; Park, K.K. The biological role of epithelial-mesenchymal transition in lung cancer (Review). Oncol. Rep. 2016, 36, 1199-1206. [CrossRef] [PubMed]

43. Horejs, C.M. Basement membrane fragments in the context of the epithelial-to-mesenchymal transition. Eur. J. Cell Biol. 2016, 95, 427-440. [CrossRef] [PubMed]

44. Deshmane, S.L.; Kremlev, S.; Amini, S.; Sawaya, B.E. Monocyte chemoattractant protein-1 (MCP-1): An overview. J. Interferon Cytokine Res. 2009, 29, 313-326. [CrossRef] [PubMed]

45. Raman, D.; Baugher, P.J.; Thu, Y.M.; Richmond, A. Role of chemokines in tumor growth. Cancer Lett. 2007, 256, 137-165. [CrossRef] [PubMed]

46. Arabzadeh, A.; Dupaul-Chicoine, J.; Breton, V.; Haftchenary, S.; Yumeen, S.; Turbide, C.; Saleh, M.; McGregor, K.; Greenwood, C.M.; Akavia, U.D.; et al. Carcinoembryonic Antigen Cell Adhesion Molecule 1 long isoform modulates malignancy of poorly differentiated colon cancer cells. Gut 2016, 65, 821-829. [CrossRef] [PubMed]

47. Ding, L.; Wang, S.; Wang, W.; Lv, P.; Zhao, D.; Chen, F.; Meng, T.; Dong, L.; Qi, L. Tanshinone IIA affects autophagy and apoptosis of glioma cells by inhibiting phosphatidylinositol 3-Kinase/Akt/Mammalian target of rapamycin signaling pathway. Pharmacology 2017, 99, 188-195. [CrossRef] [PubMed]

48. Li, X.; Li, Z.; Li, X.; Liu, B.; Liu, Z. Mechanisms of tanshinone II a inhibits malignant melanoma development through blocking autophagy signal transduction in A375 cell. BMC Cancer 2017, 17, 357. [CrossRef] [PubMed]

49. Sui, H.; Zhao, J.; Zhou, L.; Wen, H.; Deng, W.; Li, C.; Ji, Q.; Liu, X.; Feng, Y.; Chai, N.; et al. Tanshinone IIA inhibits $\beta$-catenin/VEGF-mediated angiogenesis by targeting TGF- $\beta 1$ in normoxic and HIF- $1 \alpha$ in hypoxic microenvironments in human colorectal cancer. Cancer Lett. 2017, 403, 86-97. [CrossRef] [PubMed]

50. Zhong, C.; Zhang, Y.F.; Huang, J.H.; Wang, Z.Y.; Chen, Q.Y.; Su, L.T.; Liu, Z.T.; Xiong, C.M.; Tao, Z.; Guo, R.P. The Chinese medicine, Jianpi Huayu Decoction, inhibits the epithelial mesenchymal transition via the regulation of the Smad3/Smad7 cascade. Am. J. Transl. Res. 2017, 9, 2694-2711. [PubMed]

51. Calon, A.; Espinet, E.; Palomo-Ponce, S.; Tauriello, D.V.; Iglesias, M.; Cespedes, M.V.; Sevillano, M.; Nadal, C.; Jung, P.; Zhang, X.H.; et al. Dependency of colorectal cancer on a TGF- $\beta$-driven program in stromal cells for metastasis initiation. Cancer Cell 2012, 22, 571-584. [CrossRef] [PubMed] 
52. Liu, R.Y.; Zeng, Y.; Lei, Z.; Wang, L.; Yang, H.; Liu, Z.; Zhao, J.; Zhang, H.T. JAK/STAT3 signaling is required for TGF- $\beta$-induced epithelial-mesenchymal transition in lung cancer cells. Int. J. Oncol. 2014, 44, 1643-1651. [CrossRef] [PubMed]

53. Luwor, R.B.; Baradaran, B.; Taylor, L.E.; Iaria, J.; Nheu, T.V.; Amiry, N.; Hovens, C.M.; Wang, B.; Kaye, A.H.; $\mathrm{Zhu}$, H.J. Targeting Stat 3 and Smad7 to restore TGF- $\beta$ cytostatic regulation of tumor cells in vitro and in vivo. Oncogene 2013, 32, 2433-2441. [CrossRef] [PubMed]

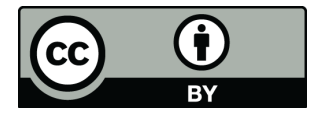

(c) 2017 by the authors. Licensee MDPI, Basel, Switzerland. This article is an open access article distributed under the terms and conditions of the Creative Commons Attribution (CC BY) license (http:/ / creativecommons.org/licenses/by/4.0/). 